\title{
Medial Prefrontal Cortex Predicts Intertemporal Choice
}

\section{Citation}

Mitchell, Jason P., Jessica Schirmer, Daniel L. Ames, and Daniel T. Gilbert. 2011. Medial Prefrontal Cortex Predicts Intertemporal Choice. Journal of Cognitive Neuroscience 23, no. 4: 857-866.

\section{Published Version}

doi:10.1162/jocn.2010.21479

\section{Permanent link}

http://nrs.harvard.edu/urn-3:HUL.InstRepos:13041325

\section{Terms of Use}

This article was downloaded from Harvard University's DASH repository, and is made available under the terms and conditions applicable to Other Posted Material, as set forth at http:// nrs.harvard.edu/urn-3:HUL.InstRepos:dash.current.terms-of-use\#LAA

\section{Share Your Story}

The Harvard community has made this article openly available.

Please share how this access benefits you. Submit a story.

Accessibility 


\title{
Medial Prefrontal Cortex Predicts Intertemporal Choice
}

\author{
Jason P. Mitchell ${ }^{1}$, Jessica Schirmer ${ }^{1}$, Daniel L. Ames ${ }^{2}$, \\ and Daniel T. Gilbert ${ }^{1}$
}

\begin{abstract}
People often make shortsighted decisions to receive small benefits in the present rather than large benefits in the future, that is, to favor their current selves over their future selves. In two studies using fMRI, we demonstrated that people make such decisions in part because they fail to engage in the same degree of self-referential processing when thinking about their future selves. When participants predicted how much they would enjoy an event in the future, they showed less activity in brain regions associated with introspective self-reference-such as the ventro-
\end{abstract}

medial pFC (vMPFC) - than when they predicted how much they would enjoy events in the present. Moreover, the magnitude of vMPFC reduction predicted the extent to which participants made shortsighted monetary decisions several weeks later. In light of recent findings that the vMPFC contributes to the ability to simulate future events from a first-person perspective, these data suggest that shortsighted decisions result in part from a failure to fully imagine the subjective experience of one's future self.

\section{INTRODUCTION}

One of the enduring mysteries of human behavior is that people who can foresee the consequences of shortsighted decisions make them anyway (Berns, Laibson, \& Loewenstein, 2007; Soman et al., 2005; Mischel, Shoda, \& Rodriguez, 1989; Ainslie, 1975). People nap when they should be working, snack when they should be dieting, spend when they should be saving - and they do these things despite knowing full well that they will regret them later. In these and other familiar instances, people consign their future selves to pay the costs they incur in the present. Why do human beings so often impose substantial burdens on their future selves to maximize immediate rewards?

One answer to this question posits that intertemporal choices-those that have consequences at more than one point in time-can be modeled as a form of intrapersonal bargaining among multiple "selves" (Ainslie, 1975, 1992; Schelling, 1984; Thaler \& Shefrin, 1981; Elster, 1979). Because predictions about what will make one's future self happy may differ from one's immediate desires in the present, intertemporal choice requires negotiating among one's competing interests at these different times ("I'd like to stay for another drink, but will probably regret it tomorrow morning"). On this view, when we successfully assign equal value to the interests of our future and present selves, we may be able to suppress our present desires in favor of a future benefit. In contrast, to the extent that we perceive our future self as "someone else"- a distinct entity whose preferences are distinct from or less impor-

${ }^{1}$ Harvard University, ${ }^{2}$ Princeton University

tant than those of our present self-we will tend to act myopically against our long-term best interests. In other words, people may tend to think of their future selves not as they think of their present selves but as they think of other people (Wakslak, Nussbaum, Liberman, \& Trope, 2008; Pronin \& Ross, 2006), and this tendency may lead them to make impatient, shortsighted decisions.

Recent neuroimaging findings provide a novel way to test this suggestion. More than a dozen studies have shown that a region of the ventromedial pFC (vMPFC) is preferentially engaged when people think about themselvesfor example, when they judge their own personality traits or report their personal preferences (for a review, see Mitchell, 2009; Uddin, Iacoboni, Lange, \& Keenan, 2007; Amodio \& Frith, 2006; Northoff \& Bermpohl, 2004)—or about those perceived to be similar to the self (Mobbs et al., 2009; Jenkins, Macrae, \& Mitchell, 2008; Mitchell, Macrae, \& Banaji, 2006). The fact that there is a wellestablished "neural signature" of self-referential processing affords a direct test of the hypothesis that shortsighted decision-making occurs in part because people fail to consider their future interests as belonging to the self: vMPFC activity should distinguish between judgments of one's present and future desires. Moreover, this difference should predict individuals' tendency to favor their present self by yielding to immediate desires instead of waiting for future rewards.

To test these predictions, participants in two experiments were scanned while completing an affective forecasting task (Gilbert \& Wilson, 2007) in which they predicted how much they would enjoy engaging in each of a series of activities (e.g., "spend the afternoon in a modern art museum") 
either in the present (the next day) or in the far future (a year later). Participants also completed one of two different intertemporal choice tasks that are commonly used to measure the extent to which people trade large future rewards for small present rewards. Finally, participants also completed an explicit self-reference task (Rogers, Kuiper, \& Kirker, 1977) used to localize a region of vMPFC preferentially engaged during introspection about oneself. We expected (a) less vMPFC activity when participants predicted their far future enjoyment than when they predicted their present enjoyment, indicating that they were not bringing to bear the same degree of self-referential processing when thinking about their future selves than their present selves, and (b) that the magnitude of this reduction in vMPFC activity would correlate with the shortsightedness of participants' intertemporal decisions some time later. In Experiment 2, we further tested the hypothesis that thinking about the future self engages the same neural processes as thinking about another person by including judgments of others as part of the affective forecasting task.

\section{METHODS}

\section{Participants}

Participants were right-handed, native English speakers with no history of neurological problems who gave consent in a manner approved by the Human Studies Committee at the Massachusetts General Hospital and the Committee on the Use of Human Subjects at Harvard University. Experiment 1 included 19 participants (13 women, mean age $=21.3$ years $)$. Experiment 2 included a different set of 19 participants (13 women, mean age $=20.9$ years).

\section{Affective Forecasting Task}

In both experiments, participants were scanned as they performed an affective forecasting task. During this task, participants indicated how much they would enjoy engaging in 120 relatively pleasurable but somewhat timeconsuming activities (such as running in a charity race or watching the sunrise) at each of two points in time: either "in the next 24 hours" (present) or "this time next year" (future). Participants responded on a 4-point scale ( $1=$ not at all to $4=$ very much). In Experiment 1 , the affective forecasting task comprised 120 predictions of enjoyment of present activities (self-present) and 120 predictions of enjoyment of future activities (self-future).

In Experiment 2, the affective forecasting task also required participants to predict another person's present and future enjoyment of activities. Before beginning the task, participants were told that research has shown that people can make accurate judgments of others with very little information. On "other" trials, participants saw a photograph of another person and were asked to use the 4-point scale to predict how much she would enjoy an activity "within the next day" or "this time next year." During scanning, "other" trials were cued with the photo of this person, whereas "self" trials were cued with a chalk outline of a head (Jenkins et al., 2008; Mitchell et al., 2006). Experiment 2 included 60 activities, which participants judged once in each of the four conditions: self-present, self-future, other-present, and other-future. In both experiments, the duration of trials was $3800 \mathrm{msec}$, divided into four functional runs of $450 \mathrm{sec}$ each.

\section{Self-reference Task}

Following the affective forecasting task in both experiments, participants completed a "self-reference" task that has frequently been used to localize brain regions that respond when people are thinking about the self (Kelley et al., 2002; for a review, see Mitchell, 2009). Across two functional runs (260 sec each), participants saw a single trait word (e.g., curious, neurotic), accompanied by a cue indicating one of two people. For "self" trials ( $n=$ 50), participants were asked to use a 4-point scale to indicate how well the trait described them. For "other" trials $(n=50)$, participants were asked to use the same scale to indicate how well the trait described George Bush (Experiment 1) or Barack Obama (Experiment 2). Our choices of "other" were guided by previous studies of self-referential thought, which have generally used judgments of the current head of state (someone who is familiar, but not personally known) as a comparison to judgments of the self (Symons \& Johnson, 1997; Rogers et al., 1977). Trials on both tasks were intermixed in a pseudorandom order and separated by a variable ISI (200$8000 \mathrm{msec}$ ) during which participants passively viewed a fixation crosshair.

\section{Intertemporal Choice Tasks}

Two different intertemporal choice tasks were used across experiments to measure individual differences in discounting of future monetary rewards. Between 12 and 110 days after scanning, 15 participants in Experiment 1 made 20 choices between a small reward to be delivered immediately (a \$10 gift certificate to Amazon.com delivered immediately via email) and a large reward to be delivered 1 month later (Becker, DeGroot, \& Marschak, 1964). Over 20 trials, the amount of the large reward increased from $\$ 11$ to $\$ 30$ in increments of $\$ 1$. Participants were informed that at the end of the experiment, one of the 20 choices would be selected randomly and enacted. The dependent measure was the smallest reward for which each participant was willing to wait 1 month.

Immediately after scanning, all participants in Experiment 2 made 144 choices between a small reward to be delivered immediately (\$10 in cash to be delivered immediately by the experimenter) or a large reward to be 
delivered at a future time (a check to be delivered by mail). The value of the large reward ranged from $\$ 12$ to $\$ 26$ in increments of $\$ 2$, and the future times were $1,7,30,60$, 180, and 365 days, resulting in 48 different large future rewards, each of which participants considered three times. Participants were informed that at the end of the experiment, one choice would be selected randomly and enacted. The dependent measure was the participant's discount rate $k$ (computed as described below).

\section{Imaging Procedure}

The same imaging parameters were used in both experiments. Functional data were collected on a 3-T Siemens Trio scanner (31 axial slices, $5 \mathrm{~mm}$ thick, $1 \mathrm{~mm}$ skip, repetition time $=2 \mathrm{sec}$, echo time $=35 \mathrm{msec}, 3.75 \times 3.75 \mathrm{in}$ plane resolution). Functional data were preprocessed and analyzed using SPM2 (Wellcome Department of Cognitive Neurology, London, UK), including slice-timing correction, normalization into the Montreal Neurological Institute anatomical space (3-mm isotropic voxels), and spatial smoothing (8-mm FWHM using a Gaussian kernel). The event-related design was modeled using a canonical hemodynamic response function. Analysis was performed individually for each participant, and contrast images were subsequently entered into a second-level analysis treating participants as a random effect. Brain regions that differentiated between conditions were identified using a statistical criterion of 90 or more contiguous voxels at a voxel-wise threshold of $p<.001$, providing an experiment-wise threshold of $p<.05$, corrected for multiple comparisons (S. Slotnick, Boston College). ANOVA procedures were conducted on the parameter estimates extracted from ROI for each trial type.

\section{RESULTS}

\section{Experiment 1}

\section{Affective Forecasting Task}

Consistent with earlier research (e.g., Zauberman \& Lynch, 2005), participants reported that they would enjoy activities more in a year $(M=2.82, S D=0.43)$ than in the next 24 hours $(M=2.63, S D=0.43), t(18)=2.31, p<.05, d=$ .54 . Response times were equivalent for future $(M=1883$ msec, $S D=355.1)$ and present $(M=1861 \mathrm{msec}, S D=$ 326.5) trials, $p>.36$.

We first examined differences in fMRI BOLD response associated with participants' predictions of their present and future enjoyment by conducting a whole-brain analysis of present $>$ future trials. Consistent with the hypothesis that predicting future enjoyment involves less self-referential processing than predicting present enjoyment, this contrast identified a sizeable region of vMPFC (Figure 1). We also observed medial parietal cortex, a region that has likewise been observed consistently during tasks that require introspection about oneself (Moran, Macrae, Heatherton, Wyland, \& Kelley, 2006; Johnson et al., 2002; Kelley et al., 2002; Zysset, Huber, Ferstl, \& von Cramon, 2002) as well as an additional locus in left occipital cortex. As in the preponderance of studies that have examined vMPFC and medial parietal cortex, modulation of activity in these regions took the form of "deactivations" relative to resting baseline (for a discussion, see Gusnard \& Raichle, 2001).

\section{Intertemporal Choice Task}

On average, participants required $\$ 14.27$ to wait 1 month in lieu of an immediate reward of $\$ 10$. Critically, the amount that participants required to wait was correlated significantly

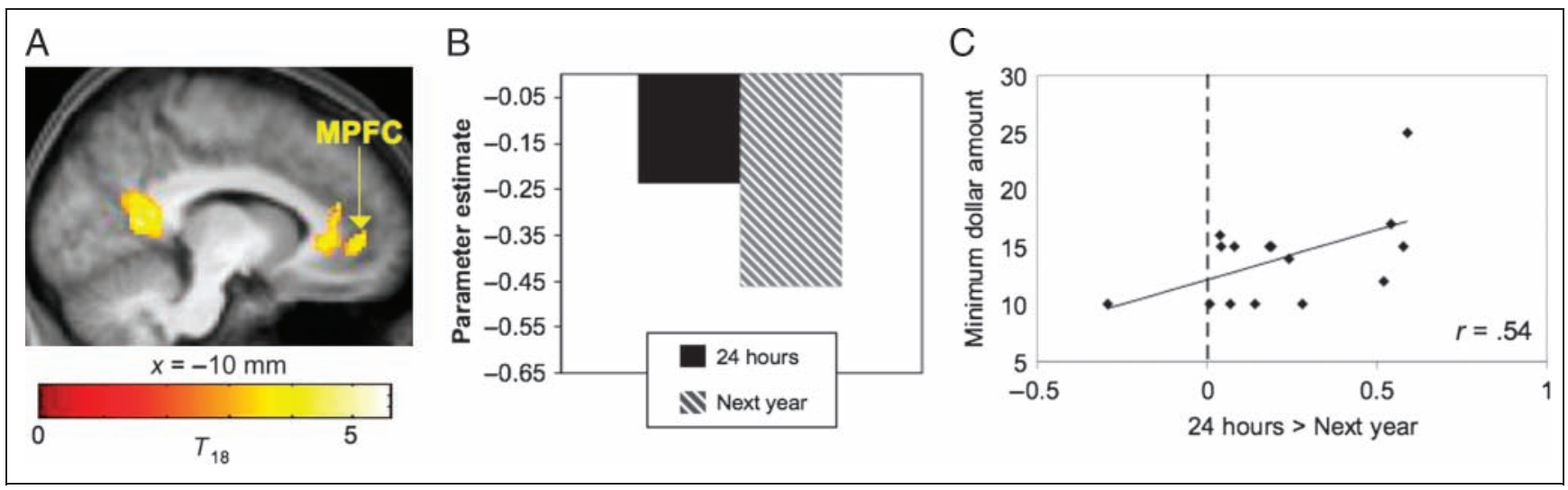

Figure 1. Brain regions that demonstrated greater activity during judgments of one's present enjoyment than future enjoyment in Experiment 1. (A) A random-effect general linear model analysis revealed three regions that were significantly more engaged by judgments of present $>$ future enjoyment, $p<.05$, corrected for multiple comparisons: the vMPFC (436 voxels in extent, centered at MNI coordinates -14 , 48, 0), the medial parietal cortex (388 voxels centered at $-16,-54,24)$, and the left occipital cortex (338 voxels centered at $-20,-80,-4)$. (B) Mean parameter estimates of this vMPFC region for present (solid black) and future (striped gray) judgments. (C) Critically, a significant relation was observed between participants' discounting of a delayed reward (measured by the minimum value that a participant required to delay receipt of a reward by 1 month) and the BOLD response difference between present and future judgments in the vMPFC. 
with vMPFC differences between predictions of present and future enjoyment. Specifically, the greater the difference in vMPFC response when participants made predictions about the present $>$ future, the more money they required to wait 1 month (Figure 1), $r(13)=.54, p<.05$; Spearman rank correlation, $\rho(13)=.44, p<.10$. This effect was specific to the vMPFC: the magnitude of the amount required to wait was not correlated with BOLD response in either medial parietal, $r(13)=-.14$, or occipital cortex, $r(13)=-.08$. This finding is all the more remarkable given that participants in Experiment 1 completed the intertemporal choice between 2 weeks and 4 months after scanning.

This effect was highlighted when we compared vMPFC activation across groups of participants defined by performance on the intertemporal choice task. "Patient" participants $(n=5)$ were willing to wait a month for even the minimum amount of $\$ 11$, whereas "impatient" participants $(n=10)$ required an average of $\$ 15.90$ to wait a month $($ range $=\$ 12-25)$. Although the vMPFC response of the patient participants did not differ between predictions of present or future enjoyment $\left(M_{\mathrm{diff}}=0.04, p>.69\right)$, the vMPFC response of the impatient participants was considerably greater when they made predictions about their present than about their future enjoyment $\left(M_{\text {diff }}=0.30\right.$, $p<.003)$. This between-group difference was supported by the marginally significant interaction of Group (patient, impatient) $\times$ Time Horizon (present, future), $F(1,14)=$ $6.01, p<.06, d=.66$.

\section{Experiment 2}

\section{Affective Forecasting Task}

As in Experiment 1, participants predicted that they would enjoy activities more in a year $(M=3.14, S D=0.58)$ than in the next 24 hours $(M=2.85, S D=0.74), t(18)=3.21$, $p<.005, d=.76$. In contrast, when judging the preferences of another person, participants differentiated only marginally between future $(M=3.27, S D=0.48)$ and present $(M=3.14, S D=0.56), t(18)=1.98, p>.06, d=.47$. That perceivers distinguished more between the future and the present for self than for other was confirmed by a significant two-way interaction of Time (present, future) $\times$ Target (self, other), $F(1,18)=4.76, p<.05$, $d=.51$. Participants' response times were equivalent for self-present $(M=1833 \mathrm{msec}, S D=230)$, self-future $(M=$ $1828 \mathrm{msec}, S D=222)$, other-present $(M=1860 \mathrm{msec}$, $S D=250)$, and other-future $(M=1849 \mathrm{msec}, S D=265)$ trials; $p>.19$ for all pairwise comparisons.

As in Experiment 1, we next examined differences in the patterns of fMRI BOLD response associated with participants' predictions of their present and future enjoyment by conducting a random-effect, whole-brain analysis of present $>$ future trials, collapsing across targets (self, other). Replicating our earlier result, this contrast identified vMPFC (Figure 2) as well as additional loci in medial parietal cortex and superior frontal gyrus. Consistent with the observation that this vMPFC region similarly distinguishes between self
Figure 2. Brain regions that demonstrated greater activity during judgments of present enjoyment than future enjoyment in Experiment 2. (A) A random-effect general linear model analysis revealed three regions that were significantly more engaged by judgments of present $>$ future enjoyment: the vMPFC (106 voxels in extent, centered at MNI coordinates 2, 56, 12), the medial parietal cortex 595 voxels centered at $0,-58,18)$, and the superior frontal gyrus (163 voxels centered at 26, 40, 50). (B) Mean parameter estimates of this vMPFC region for self-present, self-future, other-present, and other-future trials. (C) A significant relation was observed between participants' discounting of delayed rewards and the BOLD response difference between present $>$ future in the vMPFC for judgments of self (left); a marginal relation was observed for judgments of other (right)

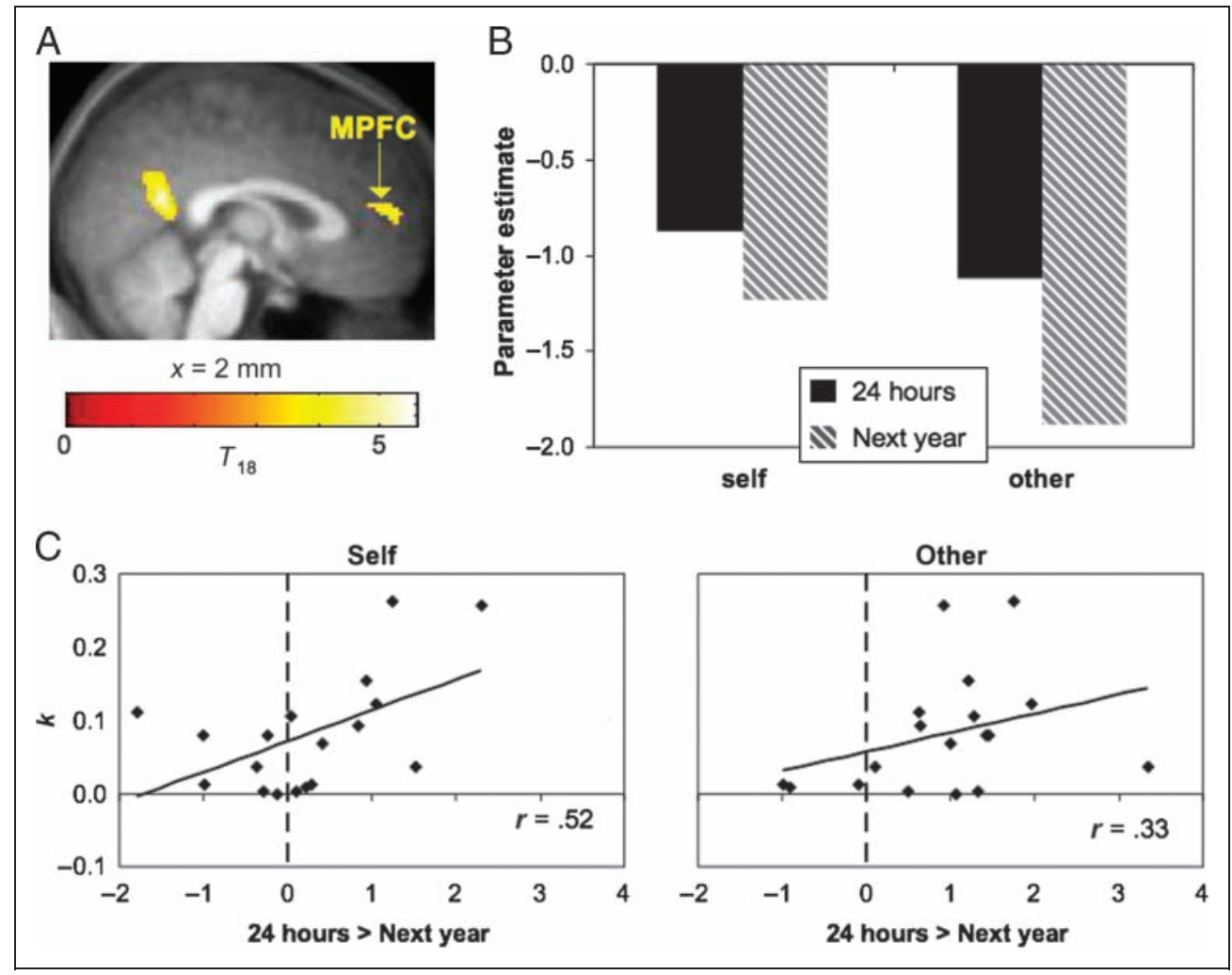


and other, analysis of the parameter estimates associated with each of the four trial types revealed significantly greater activity for judgments of self $>$ other, $F(1,18)=5.70, p<$ $.03, d=.56$. In contrast, no interaction of time and target was observed, suggesting that this region differentiated present from future thinking similarly for both self and other. Suggestively, the vMPFC difference between self-future and self-present trials was significantly correlated with the absolute difference between participants' predictions of how much they would enjoy activities at the two times, $r(17)=$ $.52, p<.03$. That is, the participants who predicted that they would enjoy an activity much more or much less in the future than in the present were the participants for whom vMPFC activity was most reduced when predicting future rather than present enjoyment. Although trending in the same direction, the corresponding value for Experiment 1 did not approach significance, $r(17)=.27, p=.26$.

\section{Intertemporal Choice Task}

On each trial, participants chose between a small immediate reward and a large future reward whose value and time of delivery varied randomly from trial to trial. On the basis of these choices, we estimated a "discount rate" (i.e., a measure of shortsightedness or impatience) for each participant. Consistent with previous findings (Laibson, 1997), the discount functions for all participants were well characterized by a hyperbolic function:

$$
\mathrm{SV}=\frac{1}{1+k D}
$$

where $S V$ is subjective value, $D$ is delay (in days), and $k$ is a participant-specific constant that corresponds to the discount rate (Kable \& Glimcher, 2007). The best fitting $k$ parameter varied widely across participants, such that our most patient participant $(k=0.002)$ was willing to wait 2 months for $\$ 12$ over an immediate gain of $\$ 10$, whereas our least patient participant ( $k=0.262$ ) preferred $\$ 10 \mathrm{im}$ mediately over $\$ 26$ in 1 week. Critically, as in Experiment 1 , the discount rate correlated significantly with the extent of vMPFC difference between predictions of future and present preferences, $r(17)=.52, p<.03 ; \rho(17)=.41 p<.10$ (see Figure 2). That is, the least patient participants (as indexed by higher $k$ values) showed the greatest reduction in vMPFC activity when predicting their own future rather than present enjoyment. Only a marginal correlation was observed between $k$ and the reduction in vMPFC activity that occurred when predicting another person's future rather than present enjoyment, $r(17)=.33, p=.16$; however, these correlations do not differ significantly from one another, $Z=0.66, p=.51$ (see Discussion). Moreover, as in Experiment 1, the participant's discount rate was significantly correlated with a reduction of activity only in vMPFC, although marginal correlations were also observed in medial parietal cortex, $r(17)=.33, p=.16$, and the superior frontal gyrus, $r(17)=.36, p=.13$.

\section{Auxiliary ROI Analysis}

We replicated the findings of both experiments in a secondary vMPFC region defined by an explicit self-reference task used to isolate brain regions preferentially engaged during introspection about the self (Kelley et al., 2002; Rogers et al., 1977). Replicating earlier studies, the contrast of self $>$ other identified a sizeable region of vMPFC in both experiments (Figure 3). We then interrogated these alternative ROI for differences in the BOLD response associated with participants' predictions of present and future enjoyment. Like the primary region of VMPFC, activity in this alternative region was greater when participants predicted present than future enjoyment: Experiment $1, F(1,18)=$ $10.89, p<.004, d=.78$; Experiment $2, F(1,18)=4.46$, $p<.05, d=.50$ (collapsing across self and other). Likewise, the BOLD difference in this region during predictions of present and future enjoyment correlated strongly with intertemporal discounting: Experiment 1, $r(13)=.64$; Experiment $2, r(17)=.47$, both $p s<.05 ; \rho(13)=.45, p<.10$ and $\rho(17)=.25, n s$, respectively. These findings are particularly compelling given that these alternative vMPFC ROIs were defined independently from a well-characterized selfreference task conducted within separate functional runs. Like the primary ROI, the vMPFC difference between selffuture and self-present trials in Experiment 2 was significantly correlated with the absolute difference between participants' predictions of how much they would enjoy activities at the two time horizons, $r(17)=.51, p<.03$; the corresponding value for Experiment 1 was $r(17)=.32, p=.18$.

\section{DISCUSSION}

The vMPFC has consistently been linked to tasks that require people to think about themselves, such as judging their own personality traits or reporting their preferences (Mitchell, 2009; Uddin et al., 2007; Amodio \& Frith, 2006; Northoff \& Bermpohl, 2004). Damage to this region impairs the ability to report a stable set of preferences (Fellows \& Farah, 2007) and leads to a broad range of deficits in assigning personal value to different outcomes (Fellows, 2006; Damasio, 1994). The present study capitalized on these observations to test the hypothesis that people who fail to engage in such self-referential processing when considering their future selves tend to prefer small rewards in the present to large rewards in the future. Consistent with this hypothesis, we observed less vMPFC activity when participants predicted how much they would enjoy an event in the future than when they estimated how much they would enjoy the same event in the present, suggesting that on average, people do not engage in self-referential processing when thinking about their future selves. Indeed, in Experiment 2, vMPFC response was nearly identical when people tried to predict their future enjoyment $(M=-1.23)$ and another person's present enjoyment $(M=-1.11)$, consistent with the notion that, in some ways, people tend to think of their future selves as they think of other people. 


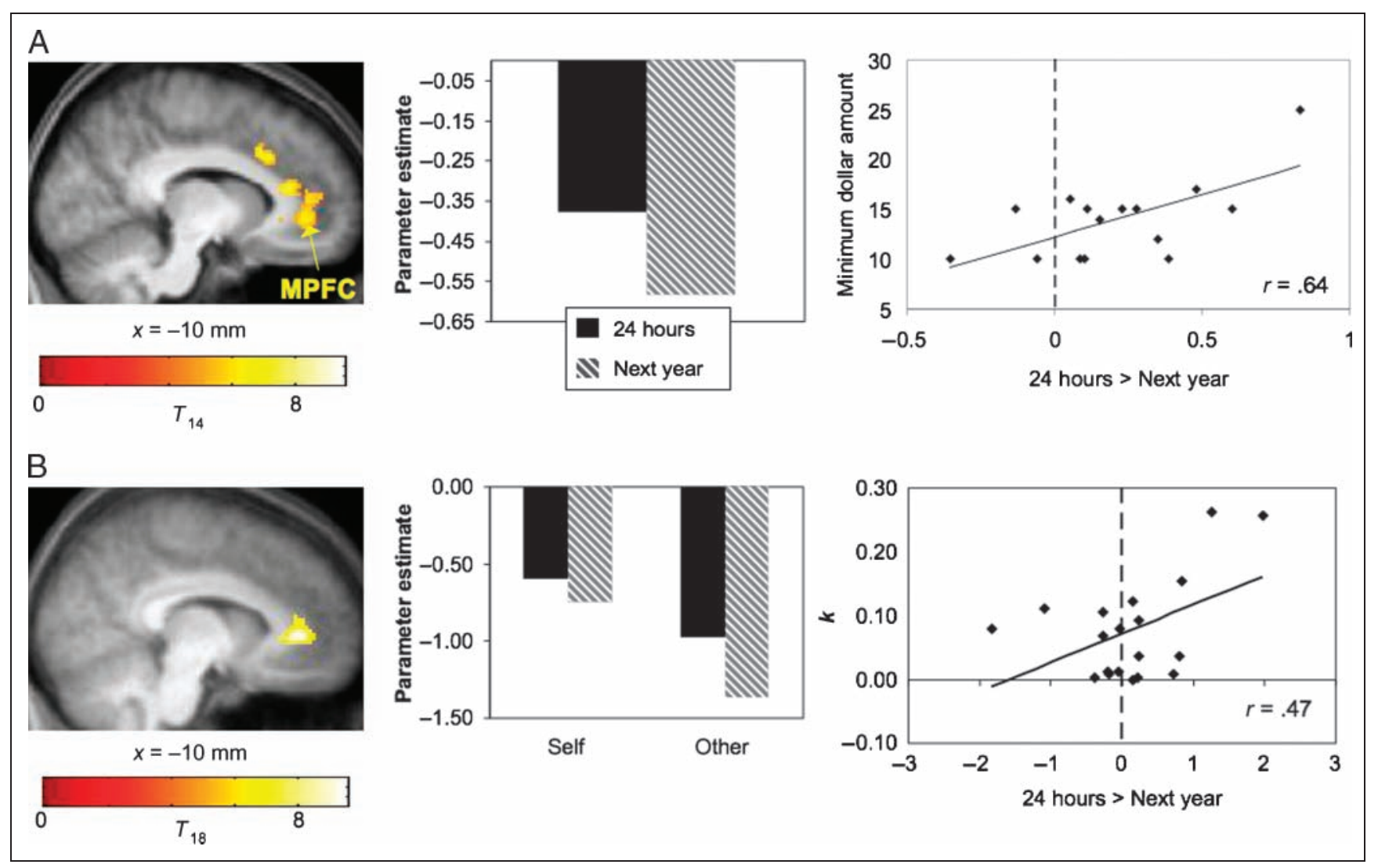

Figure 3. Secondary analyses identified a region of vMPFC from the comparison of self $>$ other on an explicit self-reference task for both (A) Experiment 1 (294 voxels centered at $-14,44,0)$ and (B) Experiment 2 (281 voxels centered at $-8,40,4), p<.05$, corrected for multiple comparisons. Middle panels display the parameter estimates extracted from these ROI on the affective forecasting task. As for the primary vMPFC regions, a significant relation was observed between participants' discounting of delayed rewards and the BOLD response difference between judgments of their present and future enjoyment of activities.

Importantly, the magnitude of this vMPFC difference between judgments of present and future enjoyment predicted the impatience or shortsightedness of people's intertemporal choices. Those participants in whom vMPFC activity most differentiated between predictions of present and future enjoyment tended to make the most impatient decisions, preferring small present rewards to large future rewards. In contrast, participants in whom vMPFC did not differentiate between predictions of present and future enjoyment tended to make the most patient decisions, preferring large future rewards to small present rewards. This correlation was observed across two different measures of intertemporal choice and in Experiment 1 was obtained despite the fact that the intertemporal choice task occurred weeks or months after scanning. Such observations suggest that the failure to think self-referentially about our future selves may represent a stable individual difference that has significant real-world consequences.

\section{Relation to Existing Research on Valuation and Decision-making}

The present results converge with those of a series of recent imaging studies that have examined the functional neuroanatomy of valuation and decision-making (Hare, Camerer, \& Rangel, 2009; Luhmann, Chun, Yi, Lee, \& Wang, 2008; Tom, Fox, Trepel, \& Poldrack, 2007; Montague, KingCasas, \& Cohen, 2006; Sanfey, Loewenstein, McClure, \& Cohen, 2006; McClure, Laibson, Loewenstein, \& Cohen, 2004; Knutson, Fong, Bennett, Adams, \& Hommer, 2003; Montague \& Berns, 2002; Breiter, Aharon, Kahneman, Dale, \& Shizgal, 2001; O’Doherty, Kringelbach, Rolls, Hornak, \& Andrews, 2001), a project sometimes described as "neuroeconomics." This work has identified two brain regions that together allow humans and other animals to evaluate different potential courses of action and their associated outcomes - the ventral striatum and the OFC. A small number of studies (Hare et al., 2009; Luhmann et al., 2008; Tom et al., 2007) have also indicated a role for a region of vMPFC similar to the one observed in the current experiments. However, exactly how the vMPFC contributes to valuation and decision-making remains unspecified, in part because researchers in this field have tended to use "vMPFC" to refer interchangeably to both the OFC and the distinct paracingulate region to which that term more typically refers, regions separated by as much as $25 \mathrm{~mm}$ (e.g., see Hare et al., 2009). Consistent with its use across the neuroimaging literature on self-reference, "vMPFC" here refers to 
an area of paracingulate cortex roughly in plane with the genu of the corpus callosum, a region whose involvement in valuation has been limited to situations in which participants choose between two alternatives, such as between monetary rewards delivered at different times (Luhmann et al., 2008; McClure et al., 2004), different monetary gambles (Tom et al., 2007), or healthy and unhealthy foods (Hare et al., 2009). Although this finding is consistent with the role of the vMPFC in reporting one's preferences and attitudes (for a review, see Mitchell, 2009), neuroeconomists have not yet clearly articulated how the valuation processes subserved by this region distinguish it from the OFC.

One such possibility is suggested by recent findings that the vMPFC plays an important role in simulating counterfactual experiences. When individuals are asked to envision a hypothetical event in the future, to remember an event from the past, or to imagine what another person feels or thinks, a set of regions that include the vMPFC is reliably engaged (Buckner \& Carroll, 2007). Importantly, vMPFC appears to contribute to such simulations to the extent that they include high levels of self-relevance, such as experiencing the scene from one's own perspective (Hassabis \& Maguire, 2009) or mentalizing about others who are highly similar to oneself (Jenkins et al., 2008; Mitchell et al., 2006). Taken together, these findings suggest that the vMPFC may contribute to valuation and preference by allowing individuals to simulate the subjective experience associated with potential events, for example, by imagining oneself engaging in an activity or experiencing some outcome and then "reading off' resulting affective states as a basis for evaluating its desirability. Situations in which one must compare multiple choices may provoke especially high levels of vMPFC activity, to the extent that they require more than one such simulation.

This account contrasts with assumptions that valuation can be accomplished by assigning stored or inferred values to different outcomes. In particular, the current data belie suggestions that the vMPFC contributes to valuation by providing a direct signal of outcome desirability, that is, by showing greater activation to positive outcomes and reduced activity to negative ones (Tom et al., 2007). In the current studies, future activities were on average rated more positively than those same events in the present. However, we observed less vMPFC activity when participants contemplated those future events, in sharp contrast to predictions that vMPFC activity correlates simply with outcome desirability. In light of the sizeable number of studies documenting the contributions of this region to selfreferential thought and to imagining one's future subjective experience, a more attractive explanation for the role of vMPFC in valuation focuses on its involvement in simulating different potential events and comparing the affective concomitants of each.

This ability to simulate counterfactual experiences may contribute to the uniquely human capacity for considering novel and hypothetical outcomes at arbitrary points in the future. Whereas other animals can wait no longer than a minute or two for a larger reward (Stevens, Hallinan, \& Hauser, 2005; Tobin, Logue, Chelonis, Ackerman, \& May, 1996; Mazur \& Logue, 1978; Ainslie, 1974), humans can delay immediate gratification indefinitely in the service of later gains (Mischel et al., 1989). Interestingly, no clear homologue for vMPFC (more specifically, the paracingulate sulcus) has been identified in monkeys (Ongur, Ferry, \& Price, 2003), suggesting that other animals may simply lack the functional architecture needed to conceive of a future self and act in its best interests (Gilbert, 2007).

\section{Relation to Existing Research on Self-reference}

Our findings also complement those of Ersner-Hershfield, Wimmer, and Knutson (2009), who identified a region of rostral ACC (rACC) that differentiated between thinking about future and present self and linked this difference to intertemporal choice. Unfortunately, Ersner-Hershfield et al. did not establish a convincing link between selfreferential processing and shortsighted intertemporal choice. The literature consistently shows that self-referential processing is associated with more anterior regions of paracingulate cortex, such as the vMPFC (as it was in our study) rather than the rACC (as it was in Ersner-Hershfield et al., 2009). Indeed, the rACC has been explicitly dissociated from self-referential processing and linked instead to stimulus valence (Moran et al., 2006), whereas vMPFC activity has been linked to the functional memory benefits associated with self-referential processing (Macrae, Moran, Heatherton, Banfield, \& Kelley, 2004). Fortunately, our studies obviate any quibbles about functional localization because of our use of an independent, explicit self-reference task that has emerged as the preferred procedure for isolating brain regions engaged by introspection about the self. Replicating more than a dozen studies (Mitchell, 2009), this task identified a region of vMPFC, in which activity not only differentiated between predictions of future and present enjoyment but also predicted intertemporal choices made weeks or months later. By independently localizing brain regions involved in making predictions about the self, these observations establish a specific link between intertemporal choice and self-referential processing. Moreover, whereas Ersner-Hershfield et al. frequently used lenient statistical criteria (as high as $p<.01$, uncorrected; see their Figure 2), we used a corrected criterion of $p<.05$ to mitigate the doubt produced by neuroimaging findings that use uncorrected statistical thresholds.

In addition to these neuroanatomical and statistical problems, Ersner-Hershfield et al. (2009) relied exclusively on an experimental task that has no conceptual relation with intertemporal choice. Specifically, their participants were scanned while making inferences about the personality traits they might possess in 10 years - a prediction that has little to do with making a choice between a small present reward and a large future reward. In contrast, our affective forecasting task - which asks people to consider how much they will enjoy activities at different points in time-has 
a demonstrable relation to intertemporal choice and is strongly predictive of individual discount rates (Kassam, Gilbert, Boston, \& Wilson, 2008).

\section{vMPFC Contributions to "Self-referential Processing"}

Throughout this article, we have described the functions subserved by the vMPFC in the very broadest manner, using the term "self-referential processing." Although this region is indeed reliably engaged during introspection about one's own preferences, emotions, and personality traits (Mitchell, 2009), referring to vMPFC processing as "self-referential" does little to explicate the precise cognitive operations carried out by this area. As reviewed above, several lines of research have made more specific suggestions about the nature of these operations, including its role in evaluating different choices and in simulating future or hypothetical experiences. Together, these different literatures suggest that vMPFC contributes to an ability to simulate subjective experiences other than the one currently being experienced, a capacity critical for evaluating the downstream consequences of a decision and for planning for future events. Although other components of the "default network" (such as posterior cingulate/precuneus) may also contribute to this ability (Buckner \& Carroll, 2007), we speculate that the vMPFC most likely contributes to such future simulation by representing the subjective affective states associated with a simulated experience.

Although we refer to such processes as "self-referential," this term should primarily be understood as an imperfect designation for a poorly characterized set of processes by which humans represent and evaluate subjective experience. Indeed, the current data themselves suggest that the response of vMPFC is modulated by more than just self-reference. For example, Experiment 2 demonstrated that vMPFC distinguished not only between introspecting about one's own preferences in the present versus future but also between judging the preferences of others at these different time horizons. This findings suggests the interesting possibility that the difficulty of representing a hypothetical experience increases linearly as that experience becomes more distant from one's own. That is, to the extent that simulating one's future experience is difficult and that simulating the experience of another person is difficult, then simulating the future experience of another person will be "doubly" difficult. This view dovetails with some accounts of "psychological distance" (Liberman \& Trope, 2008; Trope \& Liberman, 2003), which suggest that the several ways in which an event can be distant from one's own current experience (temporally, spatially, and socially) are all treated equivalently by the mind. The current data provide some indirect support for this theory by suggesting that the same brain region- $-\mathrm{vMPFC}$ - may be sensitive both to temporal distance (present vs. future) and to social distance (self vs. other); moreover, earlier work has demonstrated that this same region differentiates between similar and dissimilar others, another way to manipulate social distance (Mitchell et al., 2006). This suggestion will need to be tested further by examining whether the vMPFC is also modulated by spatial distance, that is, thinking about spatially proximal events (in the next room) compared with spatially distal events (in another country).

The preceding discussion makes clear that the field does not yet have a detailed description of the cognitive processes subserved by vMPFC. Although a better understanding of these processes is emerging rapidly from research on the neural basis of economic choice, social cognition, and memory-each of which has developed a preferred terminology for describing them-there is currently no consensus about how precisely vMPFC contributes to the human cognitive repertoire. We take comfort in the knowledge that other fields have passed through similar points in their histories: the hippocampus was once described as important for "episodic memory" (broadly construed), and researchers only later began to make more specific suggestions about how this region contributes to episodic memory, such as through associative binding (Giovanello, Schnyer, \& Verfaellie, 2004; Yonelinas, Hopfinger, Buonocore, Kroll, \& Baynes, 2001), spatial representations (Nakazawa, McHugh, Wilson, \& Tonegawa, 2004; Burgess, Maguire, \& O'Keefe, 2002), and novelty (Lisman \& Otmakhova, 2001; Knight, 1996). In much the same way, we expect that continued research across subdisciplines will help clarify how specific operations subserved by vMPFC give rise to introspective awareness.

\section{Conclusions}

The results of the current studies have important theoretical and practical consequences for decision-making. Individuals frequently commit their future selves to do certain activities (e.g., traveling to a relative's wedding, helping a friend move to a new apartment, or authoring a book chapter), and their future selves often resent those commitments when the time arrives to fulfill them (Gilbert, 2007; Zauberman \& Lynch, 2005). Why does this happen? The results of the current studies suggest that people vary in their tendency to imagine themselves experiencing future events, that individuals least prone to such self-referential simulation make the most impatient decisions, and that such differences are reflected in variability in the vMPFC. This view suggests a powerful strategy for improving intertemporal choice: When people are trying to decide whether they will want to do something in the future, they should attempt to think of themselves doing it in the present.

\section{Acknowledgments}

This work was supported by the National Science Foundation grant no. BCS 0642448 (J. P. M.). Data were collected at the Athinoula A. Martinos Center for Biomedical Imaging, which is supported by the National Center for Research Resources (grant no. P41RR14075) and the MIND Institute. 
Reprint requests should be sent to Prof. Jason Mitchell, Department of Psychology, Harvard University, Northwest Science Building, 52 Oxford Street, Cambridge, MA 02138, or via e-mail: jason_mitchell@harvard.edu.

\section{REFERENCES}

Ainslie, G. (1974). Impulse control in pigeons. Journal of the Experimental Analysis of Behavior, 21, 485-489.

Ainslie, G. (1975). Specious reward: A behavioral theory of impulsiveness and impulse control. Psychological Bulletin, 82, 463-496.

Ainslie, G. (1992). Picoeconomics: The strategic interaction of successive motivational states within the person. Cambridge: Cambridge University Press.

Amodio, D. M., \& Frith, C. D. (2006). Meeting of minds: The medial frontal cortex and social cognition. Nature Reviews Neuroscience, 7, 268-277.

Becker, G. M., DeGroot, M. H., \& Marschak, J. (1964). Measuring utility by a single-response sequential method. Behavioral Science, 9, 226-232.

Berns, G. S., Laibson, D., \& Loewenstein, G. (2007). Intertemporal choice-Toward an integrative framework. Trends in Cognitive Sciences, 11, 482-488.

Breiter, H. C., Aharon, I., Kahneman, D., Dale, A., \& Shizgal, P. (2001). Functional imaging of neural responses to expectancy and experience of monetary gains and losses. Neuron, 30, 619-639.

Buckner, R. L., \& Carroll, D. C. (2007). Self-projection and the brain. Trends in Cognitive Sciences, 11, 49-57.

Burgess, N., Maguire, E., \& O'Keefe, J. (2002). The human hippocampus and spatial and episodic memory. Neuron, 35, 625-641.

Damasio, A. R. (1994). Descartes' error. New York: Grosset/Putnam.

Elster, J. (1979). Ulysses and the sirens. Cambridge: Cambridge University Press.

Ersner-Hershfield, H., Wimmer, G. E., \& Knutson, B. (2009). Saving for the future self: Neural measures of future self-continuity predict temporal discounting. Social Cognitive and Affective Neuroscience, 4, 85.

Fellows, L. K. (2006). Deciding how to decide: Ventromedial frontal lobe damage affects information acquisition in multi-attribute decision making. Brain, 129, 944-952.

Fellows, L. K., \& Farah, M. J. (2007). The role of ventromedial prefrontal cortex in decision making: Judgment under uncertainty or judgment per se? Cerebral Cortex, 17, 2669-2674

Gilbert, D. T. (2007). Stumbling on happiness. New York: Knopf.

Gilbert, D. T., \& Wilson, T. D. (2007). Prospection: Experiencing the future. Science, 317, 1351-1354.

Giovanello, K., Schnyer, D., \& Verfaellie, M. (2004). A critical role for the anterior hippocampus in relational memory: Evidence from an fMRI study comparing associative and item recognition. Hippocampus, 14, 5-8.

Gusnard, D. A., \& Raichle, M. E. (2001). Searching for a baseline: Functional imaging and the resting human brain. Nature Reviews Neuroscience, 2, 685-694.

Hare, T. A., Camerer, C. F., \& Rangel, A. (2009). Self-control in decision-making involves modulation of the vmPFC valuation system. Science, 324, 646-648.

Hassabis, D., \& Maguire, E. A. (2009). The construction system of the brain. Philosophical Transactions of the Royal Society of London, Series B, Biological Sciences, 364, 1263-1271.

Jenkins, A. C., Macrae, C. N., \& Mitchell, J. P. (2008). Repetition suppression of ventromedial prefrontal activity during judgments of self and others. Proceedings of the National Academy of Sciences, U.S.A., 105, 4507-4512.

Johnson, S. C., Baxter, L. C., Wilder, L. S., Pipe, J. G., Heiserman, J. E., \& Prigatano, G. P. (2002). Neural correlates of self-reflection. Brain, 125, 1808-1814.

Kable, J. W., \& Glimcher, P. W. (2007). The neural correlates of subjective value during intertemporal choice. Nature Neuroscience, 10, 1625.

Kassam, K. S., Gilbert, D. T., Boston, A., \& Wilson, T. D. (2008). Future anhedonia and temporal discounting. Journal of Experimental Social Psychology, 44, 1533-1537.

Kelley, W. M., Macrae, C. N., Wyland, C. L., Caglar, S., Inati, S., \& Heatherton, T. F. (2002). Finding the self? An event-related fMRI study. Journal of Cognitive Neuroscience, 14, 785-794.

Knight, R. (1996). Contribution of human hippocampal region to novelty detection. Nature, 383, 256-259.

Knutson, B., Fong, G. W., Bennett, S. M., Adams, C. M., \& Hommer, D. (2003). A region of mesial prefrontal cortex tracks monetarily rewarding outcomes: Characterization with rapid event-related fMRI. Neuroimage, 18, 263-272.

Laibson, D. (1997). Golden eggs and hyperbolic discounting. Quarterly Journal of Economics, 112, 443-477.

Liberman, N., \& Trope, Y. (2008). The psychology of transcending the here and now. Science, 322, 1201-1205.

Lisman, J., \& Otmakhova, N. (2001). Storage, recall, and novelty detection of sequences by the hippocampus: Elaborating on the SOCRATIC model to account for normal and aberrant effects of dopamine. Hippocampus, 11, 551-568.

Luhmann, C. C., Chun, M. M., Yi, D. J., Lee, D., \& Wang, X. J. (2008). Neural dissociation of delay and uncertainty in intertemporal choice. Journal of Neuroscience, 28, 14459-14466.

Macrae, C. N., Moran, J. M., Heatherton, T. F., Banfield, J. F., \& Kelley, W. M. (2004). Medial prefrontal activity predicts memory for self. Cerebral Cortex, 14, 647-654.

Mazur, J. E., \& Logue, A. W. (1978). Choice in a "self-control" paradigm: Effects of a fading procedure. Journal of the Experimental Analysis of Behavior, 30, 11-17.

McClure, S. M., Laibson, D. I., Loewenstein, G., \& Cohen, J. D. (2004). Separate neural systems value immediate and delayed monetary rewards. Science, 306, 503-507.

Mischel, W., Shoda, Y., \& Rodriguez, M. I. (1989). Delay of gratification in children. Science, 244, 933-938.

Mitchell, J. P. (2009). Social psychology as a natural kind Trends in Cognitive Sciences, 13, 246-251.

Mitchell, J. P., Macrae, C. N., \& Banaji, M. R. (2006). Dissociable medial prefrontal contributions to judgments of similar and dissimilar others. Neuron, 50, 655-663.

Mobbs, D., Yu, R., Meyer, M., Passamonti, L., Seymour, B., Calder, A. J., et al. (2009). A key role for similarity in vicarious reward. Science, 324, 900.

Montague, P. R., \& Berns, G. S. (2002). Neural economics and the biological substrates of valuation. Neuron, 36, 265-284.

Montague, P. R., King-Casas, B., \& Cohen, J. D. (2006). Imaging valuation models in human choice. Annual Review of Neuroscience, 29, 417-448.

Moran, J. M., Macrae, C. N., Heatherton, T. F., Wyland, C. L., \& Kelley, W. M. (2006). Neuroanatomical evidence for distinct cognitive and affective components of self. Journal of Cognitive Neuroscience, 18, 1586-1594.

Nakazawa, K., McHugh, T., Wilson, M., \& Tonegawa, S. (2004). NMDA receptors, place cells and hippocampal spatial memory. Nature Reviews Neuroscience, 5 , 361-372.

Northoff, G., \& Bermpohl, F. (2004). Cortical midline structures and the self. Trends in Cognitive Sciences, 8, 102-107. 
O’Doherty, J., Kringelbach, M. L., Rolls, E. T., Hornak, J., \& Andrews, C. (2001). Abstract reward and punishment representations in the human orbitofrontal cortex. Nature Neuroscience, 4, 95-102.

Ongur, D., Ferry, A. T., \& Price, J. L. (2003). Architectonic subdivision of the human orbital and medial prefrontal cortex. Journal of Comparative Neurology, 460, 425-449.

Pronin, E., \& Ross, L. (2006). Temporal differences in train self-ascription: When the self is seen as an other. Journal of Personality and Social Psychology, 90, 197-209.

Rogers, T. B., Kuiper, N. A., \& Kirker, W. S. (1977). Self-reference and the encoding of personal information. Journal of Personality and Social Psychology, 35, 677-688.

Sanfey, A. G., Loewenstein, G., McClure, S. M., \& Cohen, J. D. (2006). Neuroeconomics: Cross-currents in research on decision-making. Trends in Cognitive Sciences, 10, 108-116.

Schelling, T. C. (1984). Self-command in practice, in policy, and in a theory of rational choice. American Economic Review, 74, 1-11.

Soman, D., Ainslie, G., Frederick, S., Li, X., Lynch, J., Moreau, P., et al. (2005). The psychology of intertemporal discounting: Why are distant events valued differently from proximal ones? Marketing Letters, 16, 347-360.

Stevens, J. R., Hallinan, E. V., \& Hauser, M. D. (2005). The ecology and evolution of patience in two New World monkeys. Biology Letters, 1, 223-226.

Symons, C. S., \& Johnson, B. T. (1997). The self-reference effect in memory: A meta-analysis. Psychological Bulletin, $121,371-394$
Thaler, R. H., \& Shefrin, H. M. (1981). An economic theory of self-control. Journal of Political Economy, 89, 392.

Tobin, H., Logue, A. W., Chelonis, J. J., Ackerman, K. T., \& May, J. G. (1996). Self-control in the monkey Macaca fascicularis. Animal Learning \& Behavior, 24, 168-174.

Tom, S. M., Fox, C. R., Trepel, C., \& Poldrack, R. A. (2007). The neural basis of loss aversion in decision-making under risk. Science, 315, 515-518.

Trope, Y., \& Liberman, N. (2003). Temporal construal. Psychological Review, 110, 401-421.

Uddin, L. Q., Iacoboni, M., Lange, C., \& Keenan, J. P. (2007). The self and social cognition: The role of cortical midline structures and mirror neurons. Trends in Cognitive Sciences, 11, 153-157.

Wakslak, C. J., Nussbaum, S., Liberman, N., \& Trope, Y. (2008). Representations of the self in the near and distant future. Journal of Personality and Social Psychology, 95, 757-773.

Yonelinas, A., Hopfinger, J., Buonocore, M., Kroll, N., \& Baynes, K. (2001). Hippocampal, parahippocampal and occipital-temporal contributions to associative and item recognition memory: An fMRI study. NeuroReport, 12, 359.

Zauberman, G., \& Lynch, J. G., Jr. (2005). Resource slack and propensity to discount delayed investments of time versus money. Journal of Experimental Psychology: General, 134, 23-37.

Zysset, S., Huber, O., Ferstl, E., \& von Cramon, D. Y. (2002). The anterior frontomedian cortex and evaluative judgment: An fMRI study. Neuroimage, 15, 983-991. 